Original Article (short paper)

\title{
Are regional differences in basketball already established in under-18 games?
}

\author{
Haruhiko Madarame ${ }^{1}$
}

\author{
${ }^{1}$ Shigakkan University, Department of Sports and Fitness, Obu, Japan
}

\begin{abstract}
Aims: To identify regional differences in basketball games for under-age categories, this study analyzed game-related statistics of four continental championships for under-18 (U18) men. Methods: A total of 149 games from each continental championship for U18 men held in 2016 were analyzed. A one-way analysis of variance followed by a Bonferroni post hoc test was performed to assess differences in game-related statistics between the continents (Europe, Africa, America, Asia). A discriminant analysis was performed to identify game-related statistics which discriminate among the continents. Results: The U18 African championship, which was characterized by a high number of free throws, was clearly discriminated from any other U18 continental championship. Among the other U18 continental championships excluding the African championship, the biggest difference was observed between the European and the Asian championships. The U18 European championship was characterized by a low number of possessions and a high number of assists, whereas the U18 Asian championship was characterized by a high number of possessions and a low number of assists. Both possessions and assists showed high numbers in the U18 American championship. Conclusion: This study identified regional differences in basketball games among four continental championships for U18 men held in 2016. It is suggested that basketball games for under-age categories are played in a different manner in each region of the world. The information derived from this study will help players and coaches of under-age national teams prepare for international competitions.
\end{abstract}

Keywords: basketball, continental difference, discriminant analysis, youth sports.

\section{Introduction}

In basketball, game-related statistics, which reflect players' behavior in the game, are recorded and summarized in a box score. In official games played under the rules of the International Basketball Federation (FIBA), the recording process is executed according to the regulations established by FIBA ${ }^{1}$, which ensure intra- and inter-operator reliability ${ }^{2}$. The FIBA regulations define eight game-related statistics: field goals, free throws, rebounds, turnovers, assists, steals, blocked shots, and fouls. Game-related statistics have been studied to scientifically illustrate the games in various categories: the Olympic Games for men $^{3,4,5}$ and women ${ }^{6}$, FIBA Basketball World Cup for $\mathrm{men}^{7}$, professional leagues for $\mathrm{men}^{8,9,10}$ and women ${ }^{11,12,13}$, and international tournaments for youth athletes ${ }^{14,15}$. In addition, game-related statistics have been analyzed in various contexts such as effects of rule changes ${ }^{16,17}$, age and sex differences ${ }^{18,19}$, and relationship with physical fitness ${ }^{20}$.

Although game-related statistics have been extensively studied, only a few studies have been performed focusing on regional differences in basketball ${ }^{21,22,23}$. Ibáñez and colleagues have recently investigated regional differences among continental championships for senior men held in 2015 and reported that each continental championship has a specific performance profile ${ }^{21}$ : Europe, a low number of possessions and a high number of assists; Africa, high numbers of free throws, rebounds, steals and fouls; America, a high number of field goal attempts; Asia, a high number of possessions and a low number of assists.

The previous findings of Ibáñez, González-Espinosa, Feu, García-Rubio ${ }^{21}$ would be useful for players and coaches of national teams preparing for international competitions. However, international competitions are held not only for senior but also for junior (under-age categories) players. Since junior games have been reported to show different characteristics compared to senior games ${ }^{18,19}$, it is uncertain that the regional differences observed among the continental championships for seniors are also observed for juniors. If regional differences among continental championships for juniors are dissimilar to those for seniors, the previous findings on seniors ${ }^{21}$ cannot be applied to juniors. Therefore, identifying regional differences in junior games would be of help for players and coaches of junior national teams to prepare for international competitions. In addition, investigating junior games would be valuable not only in terms of game preparations, but also in terms of long-term player development. Although scientific evidence related to long-term player development has been accumulating, it is still considered insufficient in the field of team sports ${ }^{24}$. Since a single study cannot provide conclusive evidence due to the complex nature of player development in team sports, studies on junior players should be conducted from various perspectives. To the best of our knowledge, no studies have investigated regional differences in junior games. Therefore, to identify regional differences in 
basketball games for under-age categories, this study analyzed game-related statistics of four continental championships for under-18 (U18) men.

\section{Methods}

\section{Sample and Variables}

Box scores of all the 149 games from each continental championship for U18 men held in 2016 (Table 1) were obtained from the official website of FIBA. In official games played under the rules of FIBA, game-related statistics are recorded according to the regulations established by FIBA ${ }^{1}$, which ensure intra- and inter-operator reliability ${ }^{2}$. In addition, a high level of inter-rater reliability has been repeatedly confirmed (kappa coefficient above 0.89$)^{4,17,21,25}$, so that official scores are treated as reliable in basketball studies ${ }^{26,27}$. Game-related statistics of each game were analyzed separately for the winning and losing teams (298 cases were analyzed in total). The analyzed game-related statistics were as follows: 2- and 3-point field goals (successful and unsuccessful), free throws (successful and unsuccessful), defensive and offensive rebounds, assists, steals, turnovers, blocks and fouls committed. To eliminate the effect of game rhythm, the variables were normalized to 100 game ball possessions ${ }^{28}$. Game ball possessions were calculated as an average of team ball possessions (TBP) of both teams ${ }^{29}$. TBP was calculated from field goal attempts (FGA), offensive rebounds (ORB), turnovers (TO) and free throw attempts (FTA) using the following equation ${ }^{29}$ :

$$
\mathrm{TBP}=\mathrm{FGA}-\mathrm{ORB}+\mathrm{TO}+0.4 \times \mathrm{FTA}
$$

Table 1. Sample characteristics.

\begin{tabular}{|c|c|c|c|}
\hline & Teams & Games & Cases \\
\hline \multirow[t]{2}{*}{ Europe } & 16 & 48 & 96 \\
\hline & $\begin{array}{l}\text { (Bosnia and Herzegovina, } \\
\text { Croatia, Finland, France, } \\
\text { Germany, Greece, Israel, Italy, } \\
\text { Latvia, Lithuania, Russia, Ser- } \\
\text { bia, Slovenia, Spain, Sweden, } \\
\text { Turkey) }\end{array}$ & & \\
\hline \multirow[t]{2}{*}{ Africa } & 11 & 39 & 78 \\
\hline & $\begin{array}{l}\text { (Algeria, Angola, Cote } \\
\text { d'Ivoire, Dem. Rep. of Congo, } \\
\text { Egypt, Gabon, Mali, Republic } \\
\text { of Benin, Rwanda, Tunisia, } \\
\text { Uganda) }\end{array}$ & & \\
\hline \multirow[t]{2}{*}{ America } & 8 & 20 & 40 \\
\hline & $\begin{array}{c}\text { (Argentina, Brazil, Canada, } \\
\text { Chile, Dominican Republic, } \\
\text { Puerto Rico, USA, Virgin } \\
\text { Islands) }\end{array}$ & & \\
\hline
\end{tabular}

\begin{tabular}{lccc}
\hline Asia & 12 & 42 & 84 \\
& $\begin{array}{c}\text { (China, Chinese Taipei, India, } \\
\text { Indonesia, Iran, Iraq, Japan, } \\
\text { Kazakhstan, Korea, Lebanon, } \\
\text { Philippines, Thailand) }\end{array}$ & & \\
& 47 & 149 & 298 \\
\hline Total & & \\
\hline
\end{tabular}

\section{Statistical Analysis}

Statistical analyses were performed with $\mathrm{R}$ version 3.3.0 for Windows ${ }^{30}$. A one-way analysis of variance (ANOVA) followed by a Bonferroni post hoc test was performed to assess differences in each variable between the continents. Cohen's $d$ was calculated as an effect size and interpreted on the same basis as the study on the senior championships ${ }^{21}(d=0.20$ to 0.49 , small effect; $d=0.50$ to 0.79 , medium effect; $d \geq 0.80$, large effect). A discriminant analysis was performed using $\mathrm{R}$ code 'candis' (http://aoki2.si.gunma-u.ac.jp/R/src/candis.R) and 'geneig' (http://aoki2.si.gunma-u.ac.jp/R/src/geneig.R) to identify game-related statistics which discriminate between the continents. An absolute value of a structural coefficient (SC) greater than or equal to 0.30 was considered relevant for the discrimination $^{21}$. Statistical significance was set at $\mathrm{P}<0.05$.

\section{Results}

Significant $F$-values were obtained for all variables except successful 2-point field goals and turnovers (Table 2). Most of the differences were found between the African and the other continental championships (Table 3). Large effect size differences between the African and the other continental championships were observed for unsuccessful free throws (vs. Europe and Asia), assists (vs. Europe and America), unsuccessful 2-point field goals (vs. America), defensive rebounds (vs. America), blocks (vs. America), team ball possessions (vs. Asia) and offensive rebounds (vs. Asia). Point difference and team ball possessions showed large effect size differences between the European and Asian championships. There were no large effect size differences between the European and American championships, and between the American and Asian championships. However, medium effect size differences were observed between the European and American championships (point difference, team ball possessions, unsuccessful 2-point field goals and blocks), and between the American and Asian championships (successful free throws and assists).

Classification results of the discriminant analysis are shown in Table 4. The total correct classification rate was $70.8 \%$. Three significant functions were obtained from the analysis (Table 5 and Figure 1). The African championship was discriminated from the other continental championships by unsuccessful free throws, defensive rebounds, offensive rebounds, assists and steals (Function 1). The European championship was discriminated from the Asian championship by ball possessions and assists (Function 2), and from the American championship by unsuccessful 2-point field goals, unsuccessful free throws and blocks (Function 3). 
Table 2. Game-related statistics of each continental championship for U18 men.

\begin{tabular}{|c|c|c|c|c|c|c|c|c|c|c|}
\hline & \multicolumn{2}{|c|}{ Europe } & \multicolumn{2}{|c|}{ Africa } & \multicolumn{2}{|c|}{ America } & \multicolumn{2}{|c|}{ Asia } & \multicolumn{2}{|c|}{ ANOVA } \\
\hline & Mean & SD & Mean & SD & Mean & SD & Mean & SD & $F$ & $P$ \\
\hline PTS & 71.7 & 11.9 & 69.5 & 20.1 & 71.6 & 15.0 & 77.0 & 17.9 & 3.08 & 0.03 \\
\hline PD & 10.5 & 8.0 & 23.9 & 24.6 & 17.4 & 12.3 & 24.3 & 19.1 & 12.37 & $<0.01$ \\
\hline TBP & 76.4 & 5.5 & 75.7 & 10.7 & 80.7 & 8.2 & 82.7 & 6.0 & 15.57 & $<0.01$ \\
\hline $\mathrm{S} 2 \mathrm{P}$ & 25.2 & 5.3 & 26.5 & 10.0 & 23.4 & 7.7 & 26.8 & 9.1 & 2.01 & 0.11 \\
\hline U2P & 28.7 & 7.0 & 26.3 & 7.7 & 33.5 & 8.9 & 31.1 & 8.2 & 9.36 & $<0.01$ \\
\hline S3P & 9.0 & 4.1 & 6.9 & 4.1 & 8.0 & 3.8 & 8.4 & 3.9 & 3.9 & $<0.01$ \\
\hline U3P & 22.8 & 6.5 & 19.0 & 7.4 & 21.8 & 6.4 & 22.3 & 7.5 & 4.87 & $<0.01$ \\
\hline SFT & 16.6 & 6.9 & 18.8 & 9.7 & 18.0 & 6.7 & 14.2 & 6.2 & 5.48 & $<0.01$ \\
\hline UFT & 7.9 & 3.8 & 14.8 & 8.0 & 9.6 & 4.9 & 8.7 & 4.4 & 26.12 & $<0.01$ \\
\hline DRB & 36.5 & 6.9 & 31.7 & 9.0 & 39.2 & 6.5 & 35.8 & 8.9 & 9.27 & $<0.01$ \\
\hline ORB & 17.7 & 6.1 & 13.8 & 7.0 & 19.2 & 6.9 & 20.2 & 6.9 & 13.29 & $<0.01$ \\
\hline AST & 20.1 & 5.9 & 13.4 & 6.9 & 19.3 & 6.3 & 15.3 & 6.2 & 19.83 & $<0.01$ \\
\hline STL & 11.4 & 3.6 & 7.8 & 6.0 & 10.9 & 4.3 & 11.8 & 5.3 & 11.13 & $<0.01$ \\
\hline TO & 22.2 & 5.1 & 21.7 & 7.3 & 21.5 & 6.3 & 22.4 & 6.3 & 0.33 & 0.81 \\
\hline BLK & 3.6 & 2.2 & 3.1 & 2.7 & 5.4 & 3.0 & 4.5 & 2.8 & 8.73 & $<0.01$ \\
\hline FC & 25.8 & 5.2 & 28.4 & 8.9 & 24.7 & 7.1 & 23.8 & 6.0 & 6.59 & $<0.01$ \\
\hline
\end{tabular}

PTS, points scored; PD, point difference; TBP, team ball possessions; S2P, successful 2-point field goals; U2P, unsuccessful 2-point field goals; S3P, successful 3-point field goals; U3P, unsuccessful 3-point field goals; SFT, successful free throws; UFT, unsuccessful free throws; DRB, defensive rebounds; ORB, offensive rebounds; AST, assists; STL, steals; TO, turnovers; BLK, blocks; FC, fouls committed. Significant P-values are shown in bold $(P<0.05)$.

Table 3. Results of post hoc comparison between each continental championship for U18 men.

\begin{tabular}{|c|c|c|c|c|c|c|c|c|c|c|c|c|}
\hline & \multicolumn{2}{|c|}{ EU-AF } & \multicolumn{2}{|c|}{ EU-AM } & \multicolumn{2}{|c|}{ EU-AS } & \multicolumn{2}{|c|}{ AF-AM } & \multicolumn{2}{|c|}{ AF-AS } & \multicolumn{2}{|c|}{ AM-AS } \\
\hline & $P$ & $d$ & $P$ & $d$ & $P$ & $d$ & $P$ & $d$ & $P$ & $d$ & $P$ & $d$ \\
\hline PTS & 1.00 & 0.13 & 1.00 & 0.01 & 0.18 & 0.36 & 1.00 & 0.11 & 0.02 & 0.40 & 0.52 & 0.32 \\
\hline PD & $<0.01$ & 0.77 & 0.23 & 0.72 & $<0.01$ & 0.96 & 0.31 & 0.31 & 1.00 & 0.01 & 0.24 & 0.40 \\
\hline TBP & 1.00 & 0.09 & 0.02 & 0.68 & $<0.01$ & 1.10 & $<0.01$ & 0.51 & $<0.01$ & 0.82 & 1.00 & 0.29 \\
\hline $\mathrm{S} 2 \mathrm{P}$ & 1.00 & 0.17 & 1.00 & 0.30 & 1.00 & 0.22 & 0.28 & 0.34 & 1.00 & 0.03 & 0.17 & 0.40 \\
\hline U2P & 0.25 & 0.33 & $<0.01$ & 0.63 & 0.26 & 0.31 & $<0.01$ & 0.89 & $<0.01$ & 0.60 & 0.65 & 0.29 \\
\hline S3P & $<0.01$ & 0.50 & 1.00 & 0.24 & 1.00 & 0.14 & 0.99 & 0.27 & 0.12 & 0.37 & 1.00 & 0.10 \\
\hline U3P & $<0.01$ & 0.55 & 1.00 & 0.15 & 1.00 & 0.07 & 0.22 & 0.40 & 0.02 & 0.45 & 1.00 & 0.07 \\
\hline SFT & 0.33 & 0.27 & 1.00 & 0.21 & 0.22 & 0.36 & 1.00 & 0.09 & $<0.01$ & 0.57 & 0.06 & 0.60 \\
\hline UFT & $<0.01$ & 1.14 & 0.71 & 0.39 & 1.00 & 0.19 & $<0.01$ & 0.74 & $<0.01$ & 0.96 & 1.00 & 0.18 \\
\hline DRB & $<0.01$ & 0.61 & 0.40 & 0.41 & 1.00 & 0.09 & $<0.01$ & 0.92 & $<0.01$ & 0.46 & 0.15 & 0.42 \\
\hline ORB & $<0.01$ & 0.59 & 1.00 & 0.23 & 0.08 & 0.39 & $<0.01$ & 0.77 & $<0.01$ & 0.92 & 1.00 & 0.15 \\
\hline AST & $<0.01$ & 1.05 & 1.00 & 0.13 & $<0.01$ & 0.79 & $<0.01$ & 0.88 & 0.34 & 0.29 & $<0.01$ & 0.64 \\
\hline STL & $<0.01$ & 0.75 & 1.00 & 0.13 & 1.00 & 0.08 & $<0.01$ & 0.57 & $<0.01$ & 0.71 & 1.00 & 0.17 \\
\hline TO & 1.00 & 0.08 & 1.00 & 0.14 & 1.00 & 0.03 & 1.00 & 0.04 & 1.00 & 0.11 & 1.00 & 0.15 \\
\hline BLK & 0.99 & 0.23 & $<0.01$ & 0.71 & 0.12 & 0.37 & $<0.01$ & 0.81 & $<0.01$ & 0.54 & 0.65 & 0.28 \\
\hline $\mathrm{FC}$ & 0.09 & 0.36 & 1.00 & 0.20 & 0.26 & 0.37 & 0.03 & 0.44 & $<0.01$ & 0.61 & 1.00 & 0.14 \\
\hline
\end{tabular}

EU, Europe; AF, Africa; AM, America; AS, Asia; PTS, points scored; PD, point difference; TBP, team ball possessions; S2P, successful 2-point field goals; U2P, unsuccessful 2-point field goals; S3P, successful 3-point field goals; U3P, unsuccessful 3-point field goals; SFT, successful free throws; UFT, unsuccessful free throws; DRB, defensive rebounds; ORB, offensive rebounds; AST, assists; STL, steals; TO, turnovers; BLK, blocks; FC, fouls committed. $P<0.05$ and $d \geq 0.80$ are shown in bold. 
Table 4. Classification results of discriminant analysis.

\begin{tabular}{cccccccc}
\hline & \multicolumn{7}{c}{ Predicted } \\
\cline { 1 - 6 } Original & \multirow{3}{*}{ Count } & Region & EU & AF & AM & AS & Total \\
& & EU & $\mathbf{7 5}$ & 7 & 2 & 12 & 96 \\
& & AF & 8 & $\mathbf{5 4}$ & 0 & 16 & 78 \\
& & AM & 11 & 1 & $\mathbf{1 8}$ & 10 & 40 \\
& & AS & 14 & 3 & 3 & $\mathbf{6 4}$ & 84 \\
\cline { 3 - 7 } & Percentage & EU & $\mathbf{7 8 . 1}$ & 7.3 & 2.1 & 12.5 & 100 \\
& & AF & 10.3 & $\mathbf{6 9 . 2}$ & 0 & 20.5 & 100 \\
& & AM & 27.5 & 2.5 & $\mathbf{4 5 . 0}$ & 25.0 & 100 \\
& & AS & 16.7 & 3.6 & 3.6 & $\mathbf{7 6 . 2}$ & 100 \\
\hline
\end{tabular}

EU, Europe; AF, Africa; AM, America; AS, Asia.

Correct classifications are shown in bold.

Table 5. Discriminant functions with structural coefficients (SC) for each variable.

\begin{tabular}{|c|c|c|c|}
\hline & Function 1 & Function 2 & Function 3 \\
\hline Eigenvalue & 0.88 & 0.46 & 0.15 \\
\hline Wilks' Lambda & 0.32 & 0.59 & 0.87 \\
\hline Chi-square & 332.2 & 151.0 & 41.2 \\
\hline Canonical correlation & 0.68 & 0.56 & 0.37 \\
\hline $\begin{array}{l}\text { Proportion of trace } \\
(\%)\end{array}$ & 58.6 & 31.1 & 10.3 \\
\hline$P$ & $<0.01$ & $<0.01$ & $<0.01$ \\
\hline Team ball possessions & 0.24 & 0.46 & 0.24 \\
\hline $\begin{array}{l}\text { Successful 2-point } \\
\text { field goals }\end{array}$ & -0.08 & 0.14 & -0.19 \\
\hline $\begin{array}{l}\text { Unsuccessful 2-point } \\
\text { field goals }\end{array}$ & 0.28 & 0.14 & 0.35 \\
\hline $\begin{array}{l}\text { Successful 3-point } \\
\text { field goals }\end{array}$ & 0.18 & -0.04 & -0.25 \\
\hline $\begin{array}{l}\text { Unsuccessful 3-point } \\
\text { field goals }\end{array}$ & 0.22 & -0.01 & -0.19 \\
\hline $\begin{array}{l}\text { Successful free } \\
\text { throws }\end{array}$ & -0.15 & -0.23 & 0.27 \\
\hline $\begin{array}{l}\text { Unsuccessful free } \\
\text { throws }\end{array}$ & -0.52 & 0.00 & 0.44 \\
\hline Defensive rebounds & 0.32 & -0.06 & 0.18 \\
\hline Offensive rebounds & 0.35 & 0.24 & -0.02 \\
\hline Assists & 0.37 & -0.42 & -0.14 \\
\hline Steals & 0.34 & 0.09 & -0.24 \\
\hline Turnovers & 0.02 & 0.04 & -0.12 \\
\hline Blocks & 0.25 & 0.16 & 0.40 \\
\hline Fouls committed & -0.24 & -0.19 & 0.01 \\
\hline
\end{tabular}

$|\mathrm{SC}| \geq 0.30$ was considered relevant for discrimination (shown in bold).

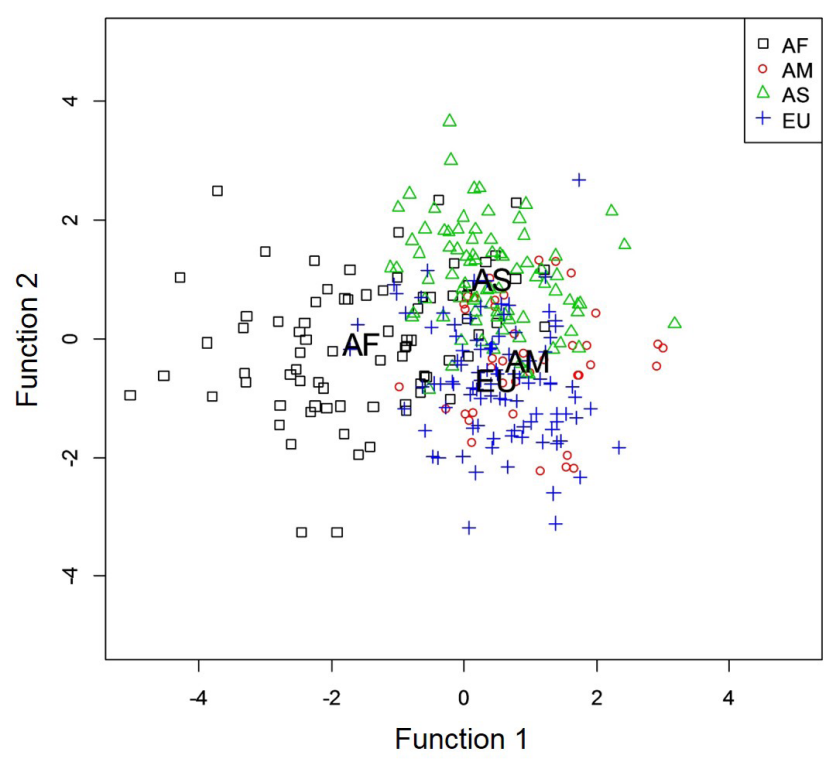

Figure 1. Territorial map of discriminant functions 1 and 2. AF, Africa; AM, America; AS, Asia; EU, Europe. Abbreviations plotted inside the figure indicate group centroids.

\section{Discussion}

To identify regional differences in basketball games for underage categories, this study analyzed game-related statistics of four continental championships for U18 men held in 2016. Significant differences were found among the continental championships, suggesting that basketball games for under-age categories are played in a different manner in each region of the world.

The U18 African championship was clearly discriminated from any other U18 continental championship. The U18 African championship was characterized by a high number of free throws. As free throws are awarded when the opposing team commits a foul, a high number of free throws reflect a high number of fouls. In fact, the number of fouls committed in the U18 African championship was the largest among the U18 continental championships. These results were in line with previously reported findings in the senior championship ${ }^{21}$. However, a difference between the U18 and the senior was also observed in the African championships. The number of steals in the African championship was the largest among the senior championships but the smallest among the U18 championships. Although a definitive conclusion cannot be made from a simple comparison between the two studies, it can be assumed that the U18 players often commit fouls when trying to steal the ball because of inadequate skills and lack of experience. A high number of fouls and/or steals would be a result of an aggressive and physical style of play, and the style of play may already be established in U18 games in Africa.

Among the other U18 continental championships excluding the African championship, the biggest difference was observed between the European and the Asian championships. The U18 
European championship was characterized by a low number of possessions and a high number of assists. It has been demonstrated that the number of assists increases with age ${ }^{18}$. In fact, the number of assists in the U18 European championship was less than that in the senior European championship ${ }^{21}(20.1$ vs. 28.1). However, the European championship showed the highest number in assists in each category of the U18 and senior continental championships. Assists have been considered as an indicator of well-organized offense, and the importance of assists has been repeatedly shown in previous studies on leagues and tournaments in Europe ${ }^{15,26,31}$. It is suggested that the style of European basketball is already established in U18 games.

In contrast to the European championship, the U18 Asian championship was characterized by a high number of possessions and a low number of assists. These results were also consistent with previously reported findings in the senior championship ${ }^{21}$. A high number of possessions indicates that the game pace was fast, and a low number of assists indicates that many points were scored after individual actions. In addition, Ibáñez and colleagues ${ }^{21}$ have pointed out that the number of possessions is related to how close or one-sided the game is, citing previous studies by Sampaio and colleagues ${ }^{26,28}$. In fact, the mean point difference between winning and losing teams in the Asian championship was the largest among the senior and U18 continental championships.

The results of discriminant analysis showed that the correct classification rate for the U18 American championship was low $(45.0 \%)$ compared to the other continental championships (Europe, 78.1\%; Africa, 69.2\%; Asia, 76.2\%). In the U18 American championship, $27.5 \%$ of the cases were misclassified into the European championship, and $25.0 \%$ of the cases were misclassified into the Asian championship. These results indicate that the homogeneity of the American championship is lower than that of the other continental championships, and some of the cases have similar characteristics to the European championship, whereas other cases have similar characteristics to the Asian championship. Nevertheless, some characteristics specific to the American championship could be found from this study. As mentioned above, the U18 European championship was characterized by a low number of possessions and a high number of assists, whereas the U18 Asian championship was characterized by a high number of possessions and a low number of assists. In contrast, both possessions and assists showed high numbers in the U18 American championship. It is likely that although the game pace in the U18 American championship was faster than that in the U18 European championship, the offense in the U18 American championship was better organized than that in the U18 Asian championship.

This study is not without limitations. Since all the data were obtained from box scores, specific elements of the game such as types of offense ${ }^{32,33}$, screens ${ }^{34,35}$ and timeouts ${ }^{36,37}$ were not analyzed in this study. In addition, future studies should also be conducted on women's games. Although women's games show different characteristics compared to men's games ${ }^{18,19}$, few studies have focused on regional differences in women's basketball.

\section{Conclusion}

This study identified regional differences in basketball games among four continental championships for U18 men held in 2016. It is suggested that basketball games for underage categories are played in a different manner in each region of the world. From a practical standpoint, the information derived from this study will help players and coaches of underage national teams prepare for international competitions. In international competitions, in contrast to domestic leagues, it is necessary to play games against relatively unfamiliar teams in a short period of time. Although detailed information about opponent teams can only be obtained through specific scouting of each opponent, basic information about opponent teams can be obtained from this study based on the continent to which each opponent belongs.

\section{References}

1. International Basketball Federation. FIBA statisticians' manual 2016. Mie, Switzerland: FIBA; 2016.

2. Sampaio J, Ibáñez SJ, Lorenzo A. Basketball. In: McGarry T, O’Donoghue P, Sampaio J, editors. Routledge handbook of sports performance analysis. Oxfordshire and New York: Routledge; 2013. pp. 357-66.

3. Leicht A, Gómez MA, Woods CT. Explaining match outcome during the men's basketball tournament at the Olympic Games. J Sports Sci Med. 2017;16(4):468-73.

4. Sampaio J, Lago C, Drinkwater EJ. Explanations for the United States of America's dominance in basketball at the Beijing Olympic Games (2008). J Sports Sci. 2010;28(2):147-52.

5. Pojskic H, Šeparović V, Užičanin E. Differences between successful and unsuccessful basketball teams on the final olympic tournament. Acta Kinesiol. 2009;3(2):110-4.

6. Leicht A, Gomez M, Woods C. Team performance indicators explain outcome during women's basketball matches at the Olympic Games. Sports. 2017;5(4):96.

7. Čaušević D. Game-related statistics that discriminated winning and losing teams from the world championships in Spain in 2014. Homo Sporticus. 2015;17(2):16-9.

8. Çene E. What is the difference between a winning and a losing team: insights from Euroleague basketball. Int J Perform Anal Sport. 2018;18(1):55-68.

9. Gómez MA, Lorenzo A, Sampaio J, Ibáñez SJ, Ortega E. Game-related statistics that discriminated winning and losing teams from the Spanish men's professional basketball teams. Coll Antropol. 2008;32(2):451-6.

10. Doğan İ, Ișik Ö, Ersöz Y. Examining the Turkish men's professional basketball team's success according to gamerelated statistics with discriminant analysis. Int J Perform Anal Sport. 2016;16(3):829-36.

11. Gómez MA, Lorenzo A, Ortega E, Sampaio J, Ibáñez SJ. Game related statistics discriminating between starters and nonstarters players in Women's National Basketball 
Association League (WNBA). J Sports Sci Med. 2009;8(2):278-83.

12. Gómez MA, Lorenzo A, Sampaio J, Ibáñez SJ. Differences in game-related statistics between winning and losing teams in women's basketball. J Hum Mov Stud. 2006;51(5):357-69.

13. Moreno E, Gómez MA, Lago C, Sampaio J. Effects of starting quarter score, game location, and quality of opposition in quarter score in elite women's basketball. Kinesiology. 2013;45(1):48-54.

14. Ibáñez SJ, Sampaio J, Saenz-Lopez P, GImenez J, Janeira MA. Game statistics discriminating the final outcome of Junior World Basketball Championship matches (Portugal 1999). J Hum Mov Stud. 2003;45:1-19.

15. Lorenzo A, Gómez MA, Ortega E, Ibáñez SJ, Sampaio J. Game related statistics which discriminate between winning and losing under-16 male basketball games. J Sports Sci Med. 2010;9(4):664-8.

16. Strumbelj E, Vracar P, Robnik-Sikonja M, Dezman B, Erculj F. A decade of euroleague basketball: an analysis of trends and recent rule change effects. J Hum Kinet. 2013;38:183-9.

17. Ibáñez SJ, García-Rubio J, Gómez MA, Gonzalez-Espinosa $\mathrm{S}$. The impact of rule modifications on elite basketball teams' performance. J Hum Kinet. in press.

18. Madarame H. Age and sex differences in gamerelated statistics which discriminate winners from losers in elite basketball games. Motriz: J. Phys. Ed. 2018;24(1):e1018153.

19. Sampaio J, Godoy SI, Feu S. Discriminative power of basketball game-related statistics by level of competition and sex. Percept Mot Skills. 2004;99(3 Pt 2):1231-8.

20. Gomes JH, Rebello Mendes R, Almeida MBd, Zanetti MC, Leite GdS, Figueira Júnior AJ. Relationship between physical fitness and game-related statistics in elite professional basketball players: Regular season vs. playoffs. Motriz: J. Phys. Ed. 2017;23(2):e101626.

21. Ibáñez SJ, González-Espinosa S, Feu S, García-Rubio J. Basketball without borders? Similarities and differences among Continental Basketball Championships. RICYDE Rev int cienc deporte. 2018;14(51):42-54.

22. Madarame H. Game-related statistics which discriminate between winning and losing teams in Asian and European men's basketball championships. Asian J Sports Med. 2017;8(2):e42727.

23. Madarame H. Defensive rebounds discriminate winners from losers in European but not in Asian women's basketball championships. Asian J Sports Med. 2018;9(1):e67428.

24. Burgess DJ, Naughton GA. Talent development in adolescent team sports: a review. Int J Sports Physiol Perform. 2010;5(1):103-16.

25. Gómez MA, Avugos S, Ángel Oñoro M, Lorenzo Calvo A, Bar-Eli M. Shaq is not alone: Free-throws in the final moments of a basketball game. J Hum Kinet. in press.

26. Garcia J, Ibáñez SJ, De Santos RM, Leite N, Sampaio J. Identifying basketball performance indicators in regular season and playoff games. J Hum Kinet. 2013;36:161-8.
27. Paulauskas P, Masiulis N, Vaquera A, Figueira B, Sampaio J. Basketball game-related statistics that discriminate between European players competing in the NBA and in the Euroleague. J Hum Kinet. in press.

28. Sampaio J, Janeira M. Statistical analyses of basketball team performance: understanding teams' wins and losses according to a different index of ball possessions. Int $\mathrm{J}$ Perform Anal Sport. 2003;3(1):40-9.

29. Oliver D. Watching a game: Offensive score sheets. Basketball on paper: Rules and tools for performance analysis. Washington D.C.: Potomac Books; 2004. pp. 8-28.

30. R Core Team. R: A language and environment for statistical computing. Vienna, Austria: R Foundation for Statistical Computing; 2016.

31. Gómez MA, Ibáñez SJ, Parejo I, Furley P. The use of classification and regression tree when classifying winning and losing basketball teams. Kinesiology. 2017;49(1):47-56.

32. Conte D, Favero TG, Niederhausen M, Capranica L, Tessitore A. Determinants of the effectiveness of fast break actions in elite and sub-elite Italian men's basketball games. Biol Sport. 2017;34(2):177-83.

33. Ciampolini V, Ibáñez SJ, Nunes ELG, Borgatto AF, Nascimento JVd. Factors associated with basketball field goals made in the 2014 NBA finals. Motriz: J. Phys. Ed. 2017;23(4):e1017105.

34. Marmarinos C, Apostolidis N, Kostopoulos N, Apostolidis A. Efficacy of the "pick and roll" offense in top level European basketball teams. J Hum Kinet. 2016;51:121-9.

35. Vaquera A, García-Tormo JV, Gómez MA, Morante JC. An exploration of ball screen effectiveness on elite basketball teams. Int J Perform Anal Sport. 2016;16(2):475-85.

36. Gómez MA, Jimenez S, Navarro R, Lago-Penas C, Sampaio J. Effects of coaches' timeouts on basketball teams' offensive and defensive performances according to momentary differences in score and game period. Eur $\mathrm{J}$ Sport Sci. 2011;11(5):303-8.

37. Sampaio J, Lago-Penas C, Gómez MA. Brief exploration of short and mid-term timeout effects on basketball scoring according to situational variables. Eur J Sport Sci. 2013;13(1):25-30.

\section{Corresponding author}

Haruhiko Madarame

Department of Sports and Fitness, Shigakkan University Nakoyama 55, Yokonemachi, Obu, Aichi 474-8651, Japan Email: madarame-tky@umin.ac.jp

Manuscript received on March 29, 2018

Manuscript accepted on June 2, 2018

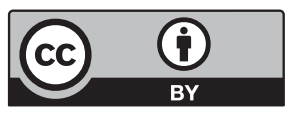

Motriz. The Journal of Physical Education. UNESP. Rio Claro, SP, Brazil - eISSN: 1980-6574 - under a license Creative Commons - Version 3.0 